\title{
mRNA-based approach to monitor recombinant gamma-interferon restoration of LPS-induced endotoxin tolerance
}

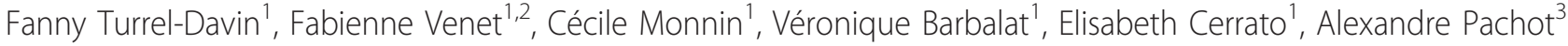 \\ , Alain Lepape ${ }^{1,4}$, Christine Alberti-Segui ${ }^{1}$ and Guillaume Monneret ${ }^{1,2^{*}}$
}

\begin{abstract}
Introduction: It is now well accepted that sepsis is associated with the development of a pronounced immunosuppressive state, characterized by severe immune alterations (e.g. reduced proliferative capacity, endotoxin tolerance, apoptosis) participating in increased mortality and susceptibility to nosocomial infections. Efforts are currently aimed at restoring a functional immune response in septic patients. Successful therapy depends on the identification of appropriate immunostimulatory drugs and on the development of suitable biomarkers that could be used to stratify patients and to follow response to treatment.

Methods: In this study, we evaluated the ex vivo effect of recombinant interferon gamma (rlFN- $\gamma$ ) in restoring monocyte functionality (endotoxin-induced Tumor Necrosis Factor- $\alpha$ production) in a two-hit model of endotoxin tolerance (ET) with peripheral blood mononuclear cells from healthy volunteers and in whole blood of septic shock patients. Importantly, we used quantitative-reverse transcription polymerase-chain reaction to monitor the effect of rIFN- $\gamma$ on the expression of seven genes known to participate in ET (TNF- $\alpha, I L-10$, HLA-DRA, CIITA, IRAK-M, ABIN-3 and (Y64).
\end{abstract}

Results: Expression analysis of those genes confirmed the presence of an immunosuppression state and the ex vivo restoration of immune functions by rIFN- $\gamma$. We show for the first time that $r \mathrm{IFN}-\gamma$ is able to bypass, at the mRNA level, the effect of negative regulators of the LPS signalling pathway such as IRAK-M, ABIN-3 and LY64.

Conclusions: Overall, mRNA expressions of a panel of genes could represent promising candidates for the ex vivo evaluation of rIFN- $\gamma$ effect on monocyte functionality. This ex vivo translational research study demonstrates the potential of a mRNA-based approach to successfully monitor drug efficacy.

\section{Introduction}

Despite advances in supportive care and a number of clinical trials, sepsis remains the leading cause of death in non-coronary ICUs [1].

With a better understanding of the pathophysiology of sepsis, it is now evident that the early pro-inflammatory phase of the disease is immediately followed by an antiinflammatory response that rapidly results in an immunosuppressive state. Immunosuppression is believed to be responsible for the increased risk of nosocomial

\footnotetext{
*Correspondence: guillaume.monneret@chu-lyon.fr

'BioMérieux, Joint Unit Hospices Civils de Lyon, Hôpital Edouard Herriot, 69003 Lyon, France

Full list of author information is available at the end of the article
}

infections and mortality [1-3] and represents an innovative target for future clinical trials. Current challenges consist of finding appropriate immunostimulant drugs, identifying patients that would benefit from immunomodulatory therapies (tailored immunotherapy) and monitoring successful response to treatment. As suggested by Carlet et al. [4], the development of biological models representative of the immunosuppressive state of the disease and the use of biomarkers may facilitate testing of immunostimulant drugs and the monitoring of response to treatment.

Among other alterations, sepsis-induced immunosuppression is characterized by dramatic monocyte/macrophage dysfunctions $[1-3,5]$. The intensity of such

\section{() Biomed Central}


dysfunctions has been correlated with an increased risk of death and nosocomial infections in septic patients. Interestingly, these alterations have been partly reproduced in an ex vivo model of endotoxin tolerance (ET). Indeed, ex vivo prior exposure of innate immune cells to minute amounts of endotoxin causes a temporary insensitivity and renders cells refractory to subsequent lipopolysaccharide (LPS) challenge [6,7]. As observed in patients, this phenomenon is associated with monocyte/ macrophage functional alterations, including a reduction in the production of pro-inflammatory cytokines associated with an increased expression of anti-inflammatory cytokines [6-10] and a decrease in antigen presenting capacity partly due to a reduced HLA-DR expression [11-15]. Moreover, LPS unresponsiveness is associated with the upregulation of numerous mechanisms that negatively regulate toll-like receptor (TLR)-associated signaling pathways $[6,7]$.

In this study we evaluated in an ex vivo experimental model of ET the potential of an immunostimulating therapy (recombinant Interferon (IFN)- $\gamma$ ) that has been proposed as a potential innovative treatment for sepsis [11-13]. Importantly, and as a proof of concept, we monitored response to treatment through the expression level of genes that have been shown in the literature to be involved in ET (TNF- $\alpha, I L-10, H L A-D R A, C I I T A$, $L Y 64, I R A K-M$ and $A B I N-3)$. Using gene expression analysis we confirmed the inflammatory properties of rIFN$\gamma$. More importantly, restoration of ET-induced monocyte dysfunction by rIFN- $\gamma$ was found in clinical samples from septic shock patients.

\section{Materials and methods \\ Preparation of PBMCs and experimental settings of ET model}

As shown in Figure 1a, human peripheral blood mononuclear cells (PBMCs) from healthy volunteers were isolated from citrated venous blood by Ficoll-Paque density gradient centrifugation (Amersham Biosciences, Björkgatan, Sweden) and washed with PBS while the remaining red blood cells were lysed. Cells were cultured in 24-well plates at $2 \times 10^{6}$ cells $/ \mathrm{ml}$ in X-Vivo 20 Medium (Lonza, Verviers, Belgium). Blood from healthy volunteers was obtained from EFS (Etablissement Francais du Sang). To induce the LPS-primed state, PBMCs were cultured in the presence or absence (control group) of $2 \mathrm{ng} / \mathrm{ml} \mathrm{LPS}$ mix from Escherichia coli O55:B5, O127:B8 and O111:B4 (Sigma-Aldrich, Deisenhofen, Germany) and incubated overnight at $37^{\circ} \mathrm{C}$ and $5 \% \mathrm{CO} 2$ (15 hours). Following a washing step, PBMCs were incubated for an additional 24 hours in the presence or absence (control group stimulated or not with LPS) of rIFN- $\gamma 1 b$ (Imukin, Boehringer, Ingelheim, Austria). Finally, cells were stimulated a second time by adding $100 \mathrm{ng} / \mathrm{ml}$ of LPS for another six hours. TNF- $\alpha$ and IL-10 protein concentrations in those supernatants were assessed as well as mRNA expressions in cell pellets. For each condition, supernatants and cell pellets were recovered and stored at $-80^{\circ} \mathrm{C}$ for TNF- $\alpha$ and IL- 10 measurements by ELISA and at $-20^{\circ} \mathrm{C}$ for RNA extractions and quantifications by quantitative-reverse transcription polymerase chain reaction (qRT-PCR), respectively.

\section{Functional testing by ELISA}

Detection of TNF- $\alpha$ and IL-10 concentrations in PBMCs culture supernatants was done by using commercially available ELISA kits from R\&D System (Minneapolis, MN, USA).

\section{RNA extraction and cDNA synthesis by reverse transcription}

Total RNA was extracted from PBMCs using RNeasy Plus Mini kits (Qiagen, Hilden, Germany) or from whole blood using QIAamp RNA Blood Mini Kit (Qiagen, Hilden, Germany). For each RNA extraction, the residual genomic DNA was digested using the gDNA Eliminator spin column (Qiagen, Hilden, Germany). RNA was diluted in $30 \mu \mathrm{l}$ of elution buffer. RNA quantity was determined for each sample using a Qubit (Invitrogen, Carlsbad, CA, USA) according to the manufacturer's instructions. Then, cDNA was synthesized from $100 \mathrm{ng}$ of total RNA using SuperScript ${ }^{\circledR}$ VILO $^{\text {TM }}$ system (Invitrogen, Carlsbad, CA, USA) according to manufacturer's instructions.

\section{Quantitative PCR analysis}

mRNA expression level was quantified using qRT-PCR. Briefly, PCR reactions were performed in a LightCycler ${ }^{\circledR}$ 480 instrument using the associated SYBR Green I Master Mix according to the manufacturer's instructions (Roche Molecular Biochemicals, Indianapolis, IN, USA). For amplification, the reaction volume was $20 \mu \mathrm{l}$, and the cycling conditions were as follows: an initial denaturation step at $95^{\circ} \mathrm{C}$ for five minutes (one cycle), followed by 45 cycles of a touch-down PCR protocol (20 seconds at $95^{\circ} \mathrm{C}, 15$ seconds annealing at 68 to $58^{\circ} \mathrm{C}$ and 15 seconds extension at $72^{\circ} \mathrm{C}$ ), a melting curve at $95^{\circ} \mathrm{C}$ for one second, $60^{\circ} \mathrm{C}$ for 10 seconds and $95^{\circ} \mathrm{C}$ for five minutes, and to finish a cooling at $40^{\circ} \mathrm{C}$ for 30 seconds. mRNA expression levels of the housekeeping gene Peptidylpropyl isomerase $B(P P I B)$, encoding for cyclophilin $\mathrm{B}$, and TNF- $\alpha$ were investigated using specific cDNA standards and ready-to-use primer mixes obtained from Search-LC (Search-LC, Heidelberg, Germany). The efficiency of PPIB mRNA levels as reference for target mRNA quantification has been previously demonstrated in human peripheral blood [16]. The PCR amplicons of the genes of interest (IL-10, HLA-DRA, CIITA, LY64, 


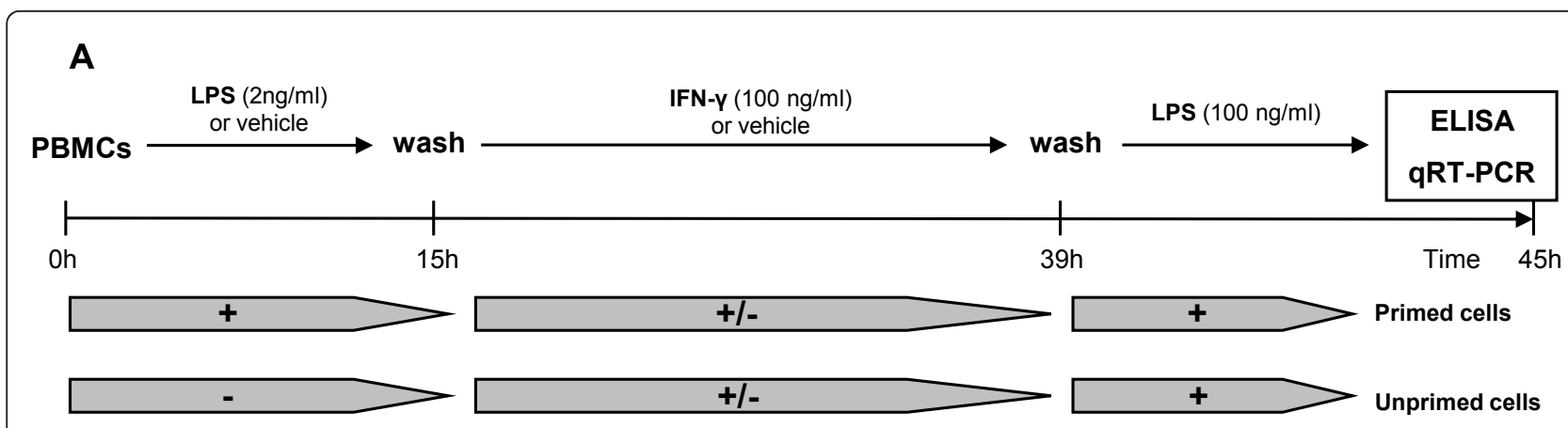

B
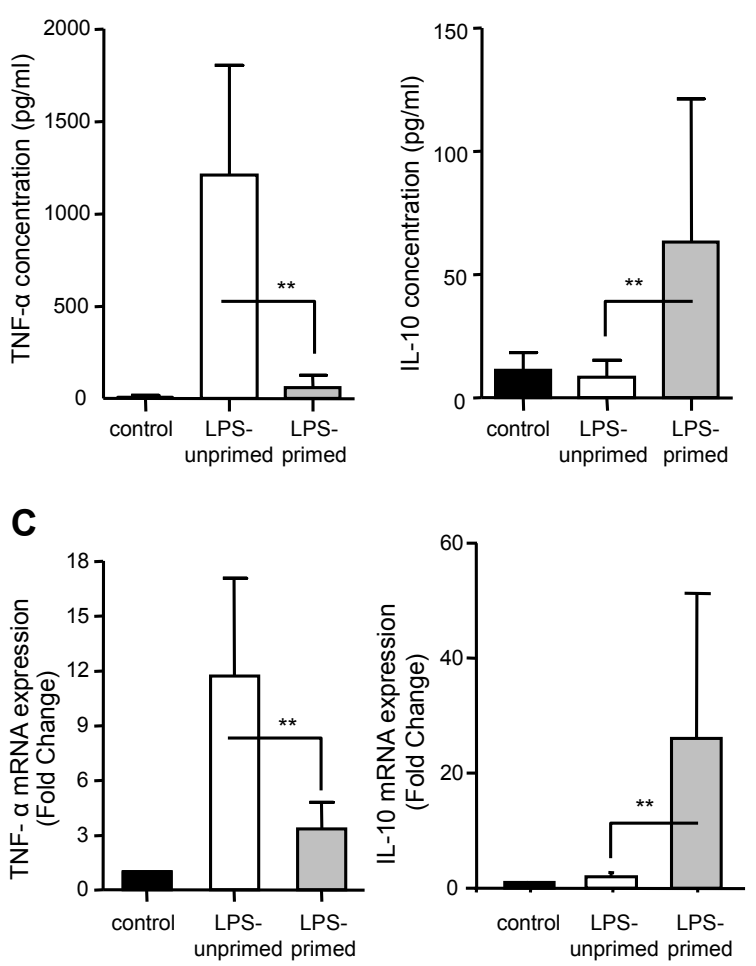

Figure 1 TNF- $\alpha$ and IL-10 protein and mRNA expressions in the ex vivo model of endotoxin tolerance. (a) Schematic representation of the endotoxin tolerance (ET) model used in the present study. (b) TNF- $\alpha$ and IL-10 protein concentrations and (c) mRNA expressions were assessed, respectively, by ELISA in culture supernatant or by quantitative RT-PCR in cell pellet obtained in peripheral blood mononuclear cells (PBMCs) after ET induction. Mean ( \pm standard deviation) data from 10 independent experiments in healthy volunteers are given. Gene expression results are presented as a normalized ratio vs data obtained in unstimulated cells (fold changes vs control). Black columns represent controls (cells without any lipopolysaccharide (LPS) stimulation), white columns indicate LPS-unprimed cells (only stimulated once with $100 \mathrm{ng} / \mathrm{ml}$ LPS) and grey columns show LPS-primed cells (two LPS stimulations: $2 \mathrm{ng} / \mathrm{ml}$ followed by $100 \mathrm{ng} / \mathrm{ml}$ ). The Wilcoxon signed rank test was used to test for statistical significance ${ }^{* *} P<0.005$ vs LPS-unprimed cells). IFN, interferon.

IRAK-M and $A B I N-3)$ were obtained with the primer combinations presented in Table 1 . Serial dilutions of the cDNA were prepared in quadruplicate to generate standard curves. Relative standard curves, describing the PCR efficiency of the genes panel and PPIB, were created and used to perform efficiency-corrected quantification with the LightCycler Software version 1.5. An internal calibrator was used to compare each cDNA amplification. The results are expressed as fold change normalized ratio of TNF- $\alpha, I L-10, H L A-D R A, C I I T A$, $L Y 64, I R A K-M$ and $A B I N-3$ mRNA relative to PPIB mRNA. qRT-PCR results were included in the analysis only when PPIB and target mRNA values were comprised within the standard curve.

\section{Septic shock patients and whole blood model}

The study group consisted of eight consecutive septic shock patients according to the diagnostic criteria of the 
Table 1 Quantitative PCR performance, parameters and primers

\begin{tabular}{ccc}
\hline Gene symbol & GenBank & Primer sequences ${ }^{\text {a }}$ \\
\hline IL-10 & NM_000572.2 & 5'-AATAAGGTTCTCAAGGGGCT-3' \\
HLA-DRA & NM_019111.4 & 5'-AGAACCAAGACCCAGACATCAA-3' \\
& & 5'-AGGGCTGTTCGTGAGCACA-3' \\
CIITA & NM_000246.3 & 5'-GCTGGGATTCCTACACAATGC-3' \\
& & 5'-CGGGTTCTGAGTAGAGCTCAATCT-3' \\
IRAK-M & NM_007199.2 & 5'-TTTGAATGCAGCCAGTCTGA-3' \\
& NM_001142523.1 & 5'-GCATTGCTTATGGAGCCAAT-3' \\
ABIN-3 & NM_024873.4 & 5'-GAATCCCAGATAAAAGCTTGT-3' \\
& NM_001128843.1 & 5'-GACAGTCTGGTGGGTGCTC-3' \\
LY64 & NM_005582.2 & 5'-GCATTGAGAAAGAAGCCAACAA-3' \\
& & 5'-GAAAAGTGTCTTCATGTATCC-3' \\
\hline
\end{tabular}

${ }^{\text {a }}$ Top sequence is forward primer, bottom is reverse

American College of Chest Physicians/Society of Critical Care Medicine [17]. Patients were admitted to the two participating ICUs (one medical, one surgical) of the Lyon-Sud University Hospital (Hospices Civils de Lyon, France). Septic shock was defined by an identifiable site of infection, evidence of a systemic inflammatory response manifested by at least two of the following criteria: a) temperature more than $38^{\circ} \mathrm{C}$ or less than $36^{\circ} \mathrm{C}$; b) heart rate above 90 beats per minute; c) respiratory rate above 20 breaths per minute; d) white blood cell count above 12,000 cells $/ \mathrm{mm}^{3}$ or less than 4,000 cells $/ \mathrm{mm}^{3}$ and hypotension persisting despite fluid resuscitation and requiring vasopressor therapy. The onset of septic shock was defined by the beginning of vasopressive therapy. The only exclusion criteria were patients younger than 18 years old and the absence of circulating leukocytes. Patients were treated according to the standardized recommendations of our ICUs. Severity at the onset of shock was assessed by the Simplified Acute Physiology Score II (SAPS II, range: 0 to 194) [18]. Development of organ dysfunctions was assessed by the Sequential Organ Failure Assessment score (SOFA, range: 0 to 24) measured after 24 hours of ICU stay [19].

EDTA whole blood was collected from eight patients within three days after the onset of shock and from eight healthy volunteers. After centrifugation and removal of plasma, $3 \mathrm{ml}$ of blood was diluted 1:1 with 3 $\mathrm{ml}$ of RPMI 1640 medium (Eurobio, Courtaboeuf, France) and then cultured in presence or absence (control group) of $100 \mathrm{ng} / \mathrm{ml} \mathrm{LPS} \mathrm{+/-} 100 \mathrm{ng} / \mathrm{ml} \mathrm{rIFN- \gamma 1 \textrm {b }}$ (Imukin, Boehringer, Ingelheim, Austria) overnight at $37^{\circ} \mathrm{C}$ and $5 \% \mathrm{CO} 2$ (15 hours). For each condition, supernatants and cell pellets were recovered and stored at $-80^{\circ} \mathrm{C}$ for TNF- $\alpha$ measurement by ELISA and at $-20^{\circ} \mathrm{C}$ for RNA extraction and quantification by qRT-PCR, respectively, as described previously in this manuscript.

\section{Flow cytometry on peripheral blood from patients}

Flow cytometric (FC500, Beckman-Coulter, Hialeah, FL, USA) expressions of cell surface markers was assessed on EDTA-anticoagulated peripheral blood from patients. Monoclonal antibodies and their respective isotype controls were used according to manufacturer's recommendation: PE-labeled anti-HLA-DR (Becton DickinsonPharmingen, San Jose, CA, USA), FITC-labeled antiCD14, ECD-labeled anti-CD4, PE-labeled anti-CD127, PECy5-labeled anti-CD25 (Immunotech, Marseille, France). Red blood cells were lysed using the automated TQ-Prep lysing system (Beckman-Coulter, Miami, FL, USA) in the case of Treg measurement or using FACS lysing solution (Becton Dickinson-Pharmingen, San Jose, CA, USA) for HLA-DR. Results are expressed as percentages of $\mathrm{CD} 4^{+} \mathrm{CD} 25^{+} \mathrm{CD} 127^{-}$cells out of the total $\mathrm{CD} 4^{+}$ lymphocytes and as percentages of cells expressing HLA-DR among total monocyte population. This work belongs to a global study on ICU-induced immune dysfunctions. It has been approved by our Institutional Review Board for ethics which waived the need for informed consent because biomarkers expression was measured on residual blood after completing routine follow-up. This study is registered at French Ministry of Research and Enseignement (\#DC-2008-509). It is also recorded at the Comission Nationale de l'Informatique et des Libertés.

\section{Statistical analysis}

Results were expressed as mean \pm standard deviation. Statistical analysis was performed using the non-parametric Wilcoxon paired test for comparison between culture conditions or using the Mann Whitney U-test for comparison between septic patients and healthy volunteers. A $P$ value less than 0.05 was considered significant with correction by the number of analyses performed.

\section{Results}

Description of the model of endotoxin tolerance (ET)

Models of ET have been characterized by a reduction of TNF- $\alpha$ production associated with an increase in IL-10 secretion following a secondary stimulation with LPS. These cytokines were therefore measured in healthy volunteers' PBMCs supernatant after two challenges with LPS (primed cells) in comparison with cells that were only stimulated with LPS at $100 \mu \mathrm{g} / \mathrm{ml}$ (unprimed cells - Figure 1a). As expected, in response to a second LPS challenge, LPS-primed cells released less TNF- $\alpha(58.5 \pm 68.3 \mathrm{pg} / \mathrm{mL})$ than unprimed cells $(1208 \pm 594 \mathrm{pg} / \mathrm{mL})$ and produced more IL-10 (63.2 \pm $58.2 \mathrm{vs} 8.4 \pm 6.9 \mathrm{pg} / \mathrm{mL}$ in unprimed cells) (Figure $1 \mathrm{~b}$ ). These results were confirmed at the mRNA level (Figure 1c). 
Therefore, this inability to produce TNF- $\alpha$ combined with an increase of IL-10 production in response to a secondary endotoxin challenge in LPS-primed cells confirmed the development of an ET state in our model.

\section{rIFN- $\gamma$ significantly improves TNF- $\alpha$ production in LPS- deactivated PBMCs}

Recombinant IFN- $\gamma$ has been proposed as a potential immunostimulating therapy in septic shock or trauma patients and preliminary clinical trials have provided encouraging results [11-13]. Therefore, we tested the effect of this drug in our model of ET.

In four preliminary experiments in healthy volunteers' PBMCs incubated with a single dose of LPS $(2 \mathrm{ng} / \mathrm{ml})$, dose effect of rIFN- $\gamma$ on TNF- $\alpha$ and $I L-10$ gene expression levels was investigated. As shown in Figure 2, rIFN$\gamma$ dose-dependently increased TNF- $\alpha$ and decreased $I L-$ 10 mRNA expression levels. On the basis of these results and in agreement with previous reports [11,20-22], cells were incubated with a drug dosage of $100 \mathrm{ng} / \mathrm{ml}$ in all further experiments.

We next investigated the effect of rIFN- $\gamma$ in 10 successive ET experiments in PBMCs from healthy volunteers. As expected, we observed that incubation of primed cells with rIFN- $\gamma$ before the second LPS challenge was associated with a significant increase of TNF- $\alpha$ concentration in the supernatant (Figure 3a). Interestingly, no effect was observed on IL-10 concentration (Figure 3b). These results were confirmed at the mRNA level as we observed a significant up-regulation of TNF- $\alpha$ mRNA expression following rIFN- $\gamma$ challenge compared with control values (Figure 4a). As shown in Figure 4b, no variation in the mRNA expression level of $I L-10$ was observed.
In addition, we monitored by qRT-PCR the expression of five genes described in the literature to be involved in the ET refractory state or sepsis-induced immunosuppression (HLA-DRA, CIITA, IRAK-M, ABIN-3, and LY64) [7]. Our results showed that, in LPS-primed cells, rIFN- $\gamma$ induced a significant up-regulation of $H L A-D R A$ and CIITA mRNA expressions (Figures 4c and 4d) associated with a significant decrease in the expression level of IRAK-M, ABIN-3 and LY64 (Figures 4e to 4g).

\section{rIFN- $\gamma$ effect on septic shock patient's whole blood}

Finally, EDTA whole blood from eight septic shock patients sampled within three days after the onset of shock was incubated with rIFN- $\gamma$. Clinical data are presented in Table 2. At the time of sampling, these patients presented with a reduced percentage of HLADR expressing monocytes (60\%/39-67), Median/Q1-Q3), a marked lymphopenia $\left(0.6 \times 10^{3}\right.$ lymphocytes/ $\mu$ l $(0.6$ 1)) and an increased percentage of circulating Treg cells (11\%/10-13). As expected, in response to LPS, patients produced lower amount of TNF- $\alpha$ and significantly more IL-10 protein than healthy controls (Figures $5 \mathrm{a}$ and $5 \mathrm{~b}$ ). These results were confirmed at the mRNA level (Figures $6 \mathrm{a}$ and $6 \mathrm{~b}$ ). Importantly, the addition of rIFN- $\gamma$ significantly restored TNF- $\alpha$ and abrogated IL10 productions (Figures $5 \mathrm{a}$ and $5 \mathrm{~b}$ ). Those variations were observed at the mRNA level in septic shock patients (Figures 6a and 6b). Moreover and as observed in our model of ET, rIFN- $\gamma$ induced a massive elevation of HLA-DRA and CIITA mRNA expression levels but had no effect on IRAK-M and LY64 (Figures 6c to 6f). $A B I N-3$ mRNA expression level has a similar behavior as IRAK-M. However, we could not conclude on ABIN-
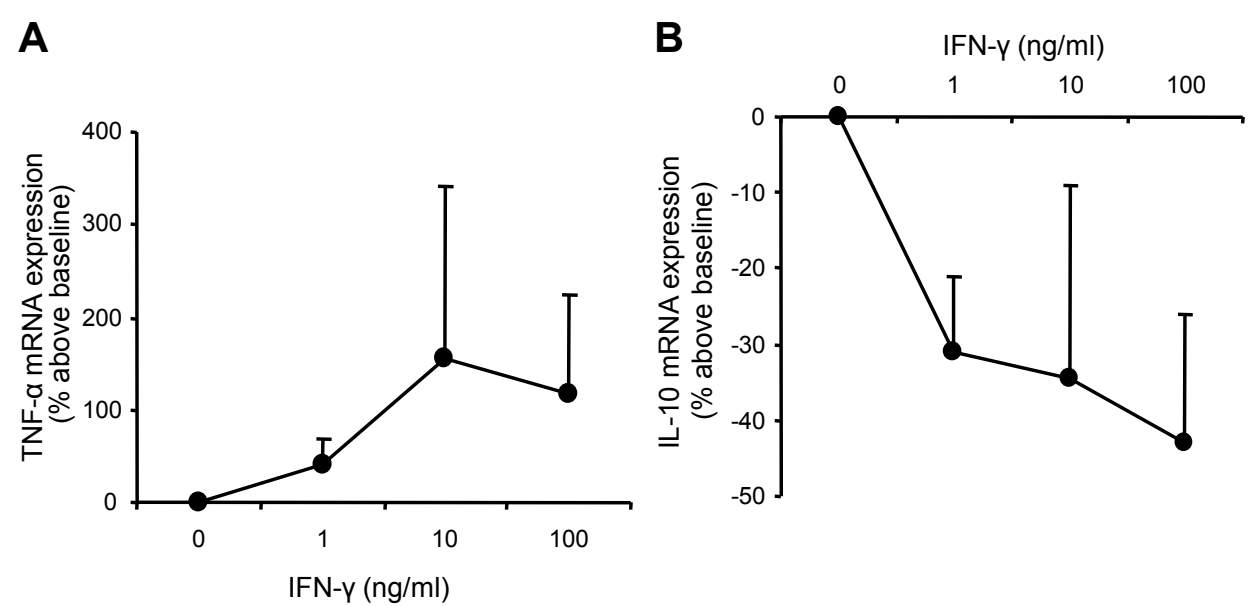

Figure 2 Recombinant IFN- $\boldsymbol{\gamma}$ dose-response curves. mRNA expressions of (a) TNF- $\alpha$ and (b) IL-10 were quantified by quantitative RT-PCR in peripheral blood mononuclear cells (PBMCs) from four healthy volunteers after lipopolysaccharide (LPS) incubation (2 ng/ml for 15 hours) and treatment with or without (baseline) rlFN- $\gamma 1 \mathrm{~b}$ (at 1, 10 or $100 \mathrm{ng} / \mathrm{ml}$ ) for 24 hours. Values are presented as means and standard deviations of percentage above baseline. IFN, interferon. 


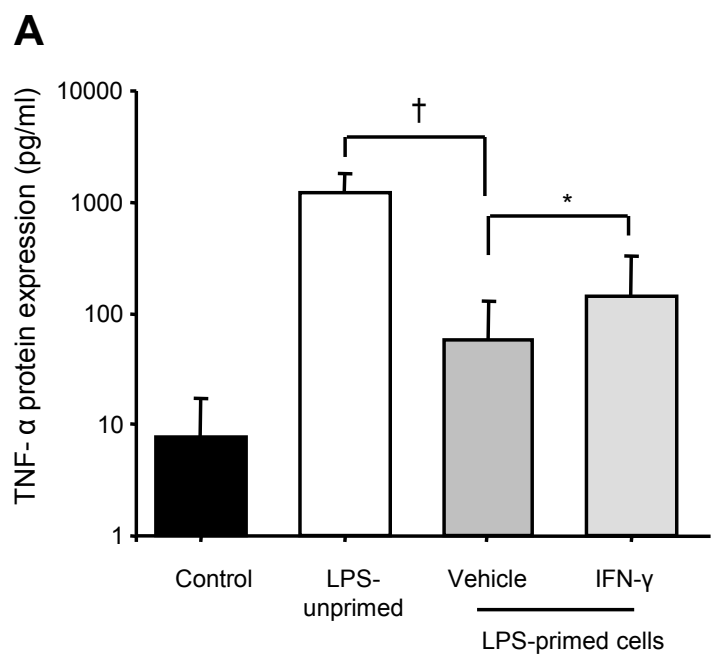

B

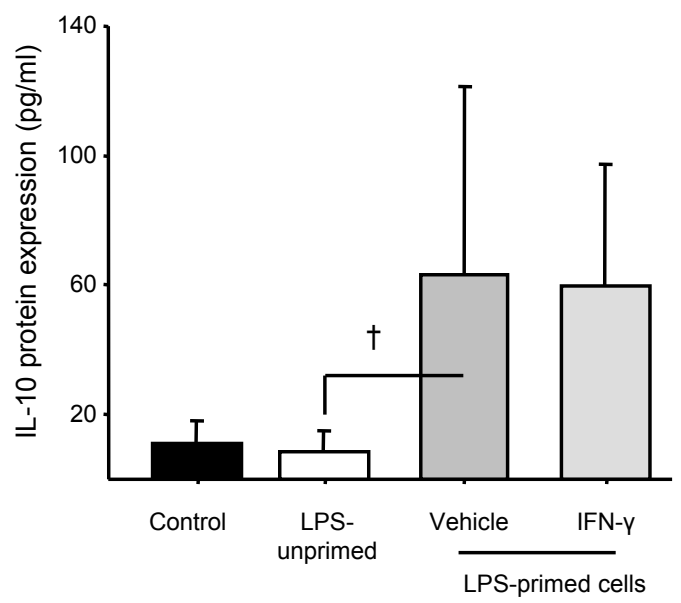

Figure 3 Effect of recombinant IFN- $\gamma$ on TNF- $\alpha$ and IL-10 protein expressions. (a) TNF- $\alpha$ and (b) IL-10 protein concentrations were assessed by ELISA in culture supernatants obtained after endotoxin tolerance (ET) induction in peripheral blood mononuclear cells (PBMCs) from 10 healthy individuals. Mean ( \pm standard deviation) data are given. Black columns represent controls (cells without any lipopolysaccharide (LPS) stimulation), white columns indicate LPS-unprimed cells (only stimulated once with $100 \mathrm{ng} / \mathrm{ml}$ LPS) and dark gray columns show LPS-primed cells (two LPS stimulations: $2 \mathrm{ng} / \mathrm{ml}$ followed by $100 \mathrm{ng} / \mathrm{ml}$ ) and light grey show LPS-primed cells incubated with $\mathrm{rlFN}-\gamma 1 \mathrm{~b}(100 \mathrm{ng} / \mathrm{ml})$. The Wilcoxon signed rank test was used to test for statistical significance ( $P$ P $<0.005$ vs LPS-unprimed cells; $P<0.05$ vs vehicle). IFN, interferon.

3 since its mRNA values for control conditions (nonstimulated cells) were below the lowest values of the standard curve (data not shown).

\section{Discussion}

It is now largely accepted that sepsis is characterized by the development of profound immune dysfunctions $[1,2,23]$. Such alterations could explain patients' inability to fight the primary bacterial infection and their decreased resistance to secondary nosocomial infections. As a consequence, sepsis-induced immune dysfunctions may contribute largely to mortality. Among mechanisms responsible for this immunosuppression, monocyte dysfunction, generically called ET, is believed to play a pivotal role $[2,6,7,24]$. Clinically, the state of ET is associated with functional and phenotypic alterations of circulating monocytes. It has been demonstrated that patients with the most severe monocyte dysfunctions are those who have a greater risk of developing nosocomial infections and a greater risk of dying $[14,15,25]$. Overall, these observations provide a rational for the development of novel therapies aimed at boosting the immune functions in septic patients.

ET can be partly mimicked ex vivo when cells from healthy volunteers are activated by sequential LPS challenges $[24,26,27]$. Here, we took advantage of this model to investigate the effects of a pro-inflammatory drug, rIFN- $\gamma$, which previously provided interesting preliminary results in small clinical studies [11-13]. We assessed ex vivo drug effect through the monitoring of the expression level of a panel of seven genes (i.e. TNF- $\alpha$, IL-10, HLA-DRA, CIITA, IRAK-M, ABIN-3 and LY64).

In the present experiments, we observed that rIFN- $\gamma$ restored ex vivo the production of the pro-inflammatory cytokine TNF- $\alpha$, therefore reflecting monocyte function improvement. We observed an increase in the expressions of TNF- $\alpha, H L A-D R A$ and CIITA mRNA following rIFN $-\gamma$ treatment in our model of ET. Importantly, a similar increase in the expression of those genes was also observed in the whole blood of septic shock patients upon ex vivo rIFN- $\gamma$ challenge. Our data are in agreement with previous literature $[9,11]$. The positive effect of rIFN- $\gamma$ could be explained, in part, by the ability of IFN- $\gamma$ to enhance NF- $\kappa$ B nuclear translocation in response to LPS [20] and to induce recruitment of transcription factors. Restoration of the accessibility to endogenous promoters, in part by facilitating TLRinduced chromatin remodeling [28], may also explain the positive effect of rIFN- $\gamma$ on monocyte functionality.

Regarding the negative regulators of LPS signaling pathway, we observed, in our model of ET, an increase in the mRNA expression level of IRAK-M and ABIN-3. It is important to note that these results are in agreement with previous reports $[29,30]$. However, to our knowledge, we show for the first time that rIFN- $\gamma$ induced ex vivo a restoration of the TLR signaling pathway, by decreasing both $I R A K-M$ and $A B I N-3$ mRNA expression levels. Such variation in gene expression induced by rIFN- $\gamma$ might add to the understanding of cell function recovery. In this model of ET, LY64 gene 

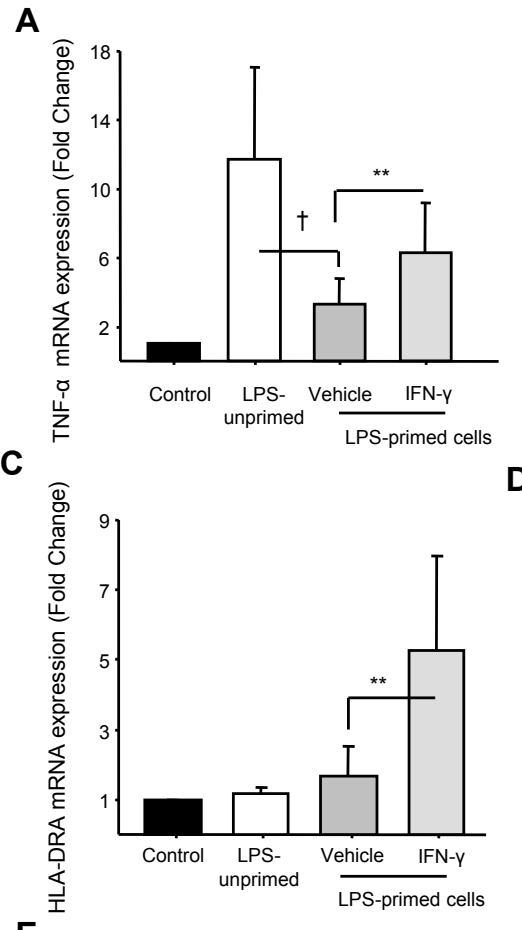

E

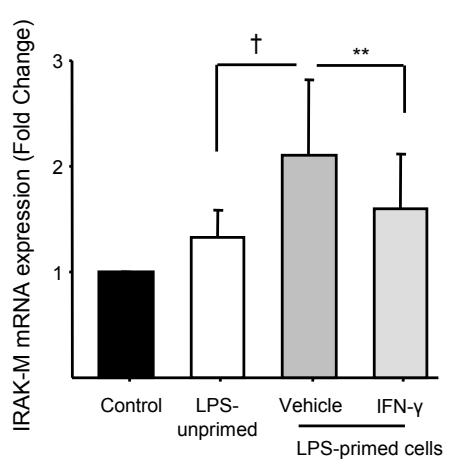

G

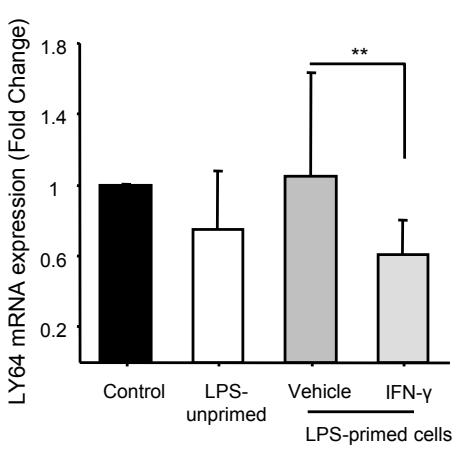

B

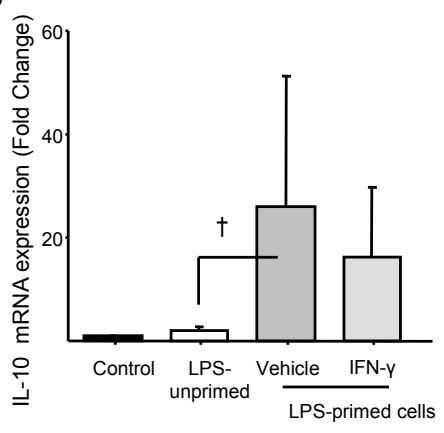

D $\widehat{\Phi}$

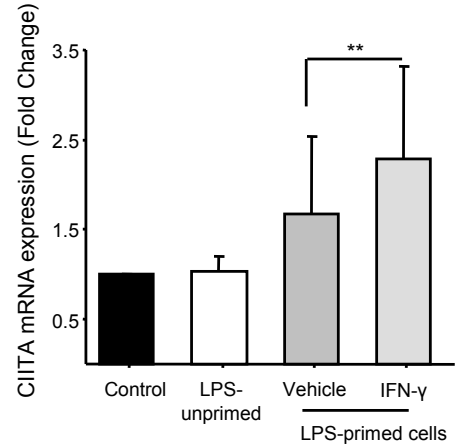

$\mathbf{F}$

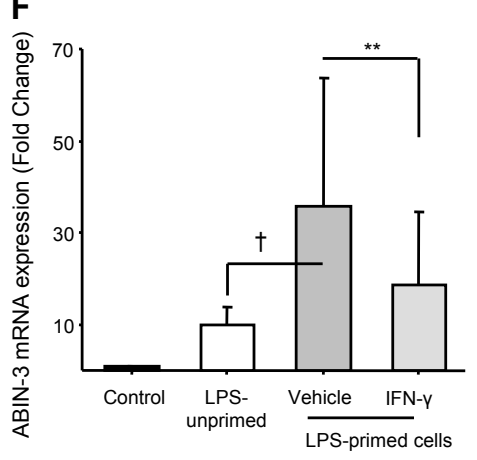

Figure 4 mRNA expression analysis of seven genes after incubation with recombinant IFN- $\gamma$ in the ex vivo model of endotoxin tolerance. mRNA expressions of (a) TNF- $\alpha$, (b) IL-10, (c) HLA-DRA, (d) CIITA, (e) IRAK-M, (f) ABIN-3 and (g) LY64 were quantified by quantitative RT-PCR in peripheral blood mononuclear cells (PBMCs) from 10 healthy volunteers after induction of endotoxin tolerance. Black columns represent controls (cells without any lipopolysaccharide (LPS) stimulation), white columns indicate LPS-unprimed cells (only stimulated once with $100 \mathrm{ng} / \mathrm{ml}$ LPS) and dark grey columns show LPS-primed cells (two LPS stimulations: $2 \mathrm{ng} / \mathrm{ml}$ followed by $100 \mathrm{ng} / \mathrm{ml}$ ) and light grey show LPSprimed cells incubated with rlFN- $\gamma 1 \mathrm{~b}(100 \mathrm{ng} / \mathrm{ml})$. Gene expression results are presented as a normalized ratio vs data obtained in unstimulated cells (fold changes vs control). Data are presented as mean \pm standard deviation. The Wilcoxon signed rank test was used to test for statistical significance ( $P<0.005$ vs LPS-unprimed cells; ${ }^{* *} P<0.005$ vs vehicle). IFN, interferon. 
Table 2 Demographic and clinical data for septic shock patients

\begin{tabular}{cc}
\hline Parameters & Patients $(\boldsymbol{n}=\mathbf{8})$ \\
\hline Age at admission (years) & $75(64-79)$ \\
Gender (male) & $6(75 \%)$ \\
SOFA score & $11(11-12)$ \\
SAPS II score & $55(48-64)$ \\
\% HLA-DR ${ }^{+}$monocytes & $60(39-67)$ \\
\% of regulatory T cells (among CD4 ${ }^{+}$lymphocytes) & $11(10-13)$ \\
Number of lymphocytes $\left(10^{3} / \mu\right.$ ) & $0.6(0.6-1)$ \\
Sampling time (Days after shock) & $1(1-1)$ \\
Mortality (survivors) & $4(50 \%)$ \\
\hline
\end{tabular}

Results are presented as median and interquartile range (Q1-Q3) for continuous variables or as number of cases and percentages (\%) for categorical data.

SAPS II, Simplified Acute Physiology Score II measured on admission; SOFA score, Sequential Organ Failure Assessment measured during the first 24 hours of ICU stay.

expression, which is also a TLR4 signaling pathway regulator, was decreased as well in the presence of rIFN- $\gamma$. The exact role of LY64 on TLR signaling pathways is not yet clearly established [25,31] and additional experiments are needed to further address this point.

Regarding the effect of rIFN- $\gamma$ on IL-10 expression, we observed discrepant results between the ET model on healthy PBMCs and the ex vivo stimulation in whole blood of septic patients. Indeed, at the protein and mRNA levels, rIFN- $\gamma$ did not result in a decrease of IL10 in LPS-deactivated PBMCs. In a similar experimental model, Randow et al. showed an increase in the IL-10 production in refractory cells exposed to IFN- $\gamma$ [22]. In contrast we found that the $I L-10$ gene was down-regulated by rIFN- $\gamma$ in whole blood cells from septic shock patients. These results are in agreement with Nakos et al. who observed that the administration of inhaled IFN $-\gamma$ in immunoparalyzed patients resulted in an increase of pro-inflammatory markers and a decrease of anti-inflammatory molecules like IL-10 [13].

Importantly, this study highlights the potential of using gene expression analysis to identify novel biomarkers that could contribute to a more personalized medicine. It is now well established that biomarkers will be useful (i) to identify patients eligible for immunomodulatory therapies, (ii) to monitor response to treatment, and (iii) to evaluate benefit/risk ratio. So far, flow cytometric measurement of HLA-DR expression on circulating monocytes has appeared as a reliable biomarker for the prediction of death and nosocomial infections in septic patients $[14,15,32]$. Small clinical trials have used this parameter to stratify ICU patients before administration of rIFN- $\gamma[11,13]$. However, pre-analytical and analytical issues inherent to HLA-DR measurement by flow cytometry limit its use in large multicentered clinical studies and on a routine basis [33]. Based on the results of the current study and on previous investigations showing the correlation between mRNA and protein expression levels for this parameter [32,34], HLA$D R$ and CIITA mRNA measurements appear as promising gene candidates for the monitoring of response to immunomodulatory therapies. This is all the more because the availability in routine labs of molecular biology platforms will enable standardized and routine use of such biomarkers.

In total, given that gene expression profiling is now recognized to offer meaningful data, it provides a new perspective in the prognosis and monitoring of septic patients and offers the foundation for possible automated tests with standardized methodologies. As an
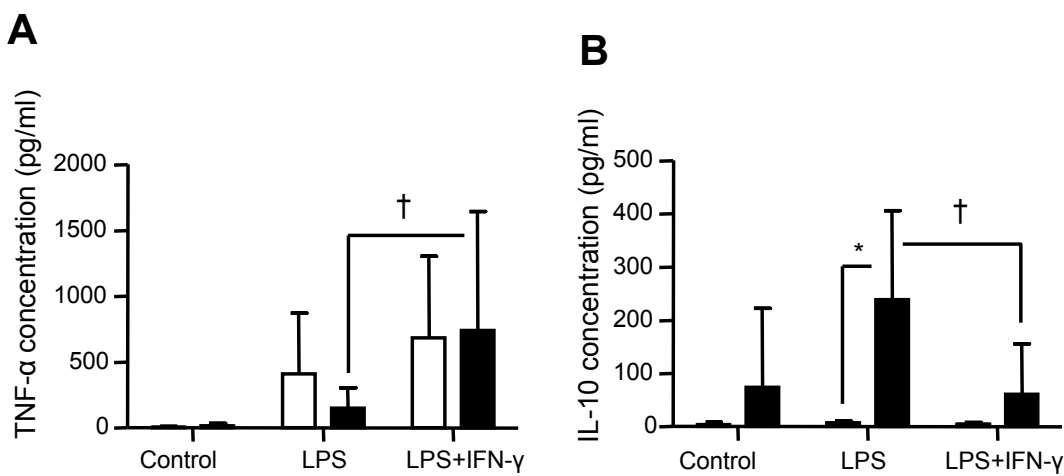

Figure 5 TNF- $\alpha$ and IL-10 productions after incubation with recombinant IFN- $\gamma$ and LPS in whole blood from septic shock patients. (a) TNF- $\alpha$ and (b) IL-10 protein expressions were assessed by ELISA, in EDTA whole blood supernatants after incubation with or without lipopolysaccharide (LPS; $100 \mathrm{ng} / \mathrm{ml})$ and $\mathrm{rIFN}-\gamma(100 \mathrm{ng} / \mathrm{ml})$. Results were obtained from eight septic shock patients sampled within three days after the onset of shock (black columns) and eight healthy volunteers (open columns) stimulated or not (control group) with LPS in absence or in presence of riFN- $\gamma$ overnight. Data are presented as mean \pm standard deviation. Comparison between healthy volunteers and septic shock patients was performed using the Mann-Whitney $U$ test $(* P<0.05)$ whereas evaluation of rlFN-y effect was performed using the Wilcoxon signed rank test $(+P<0.05)$. IFN, interferon. 


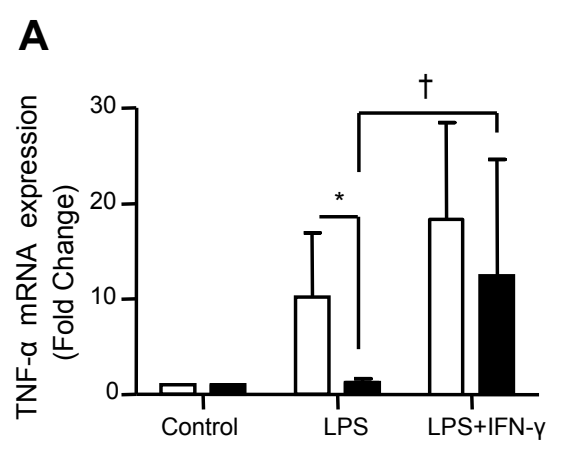

\section{C}

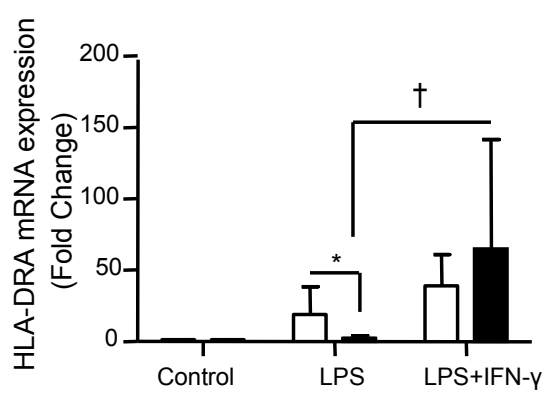

E

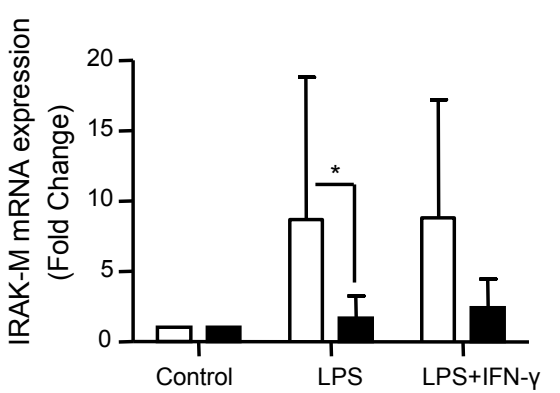

B

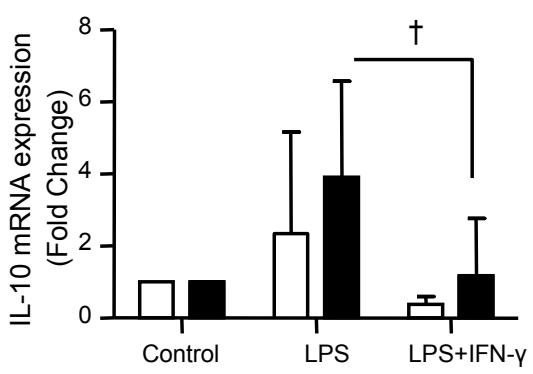

D

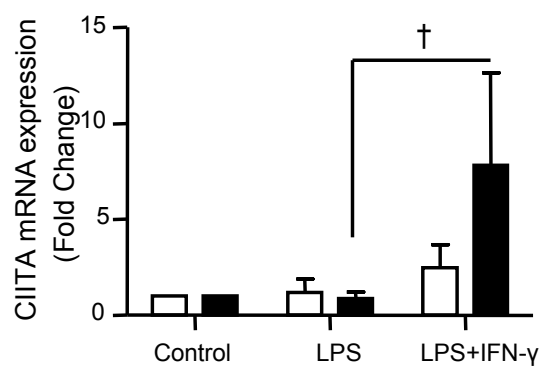

$\mathbf{F}$

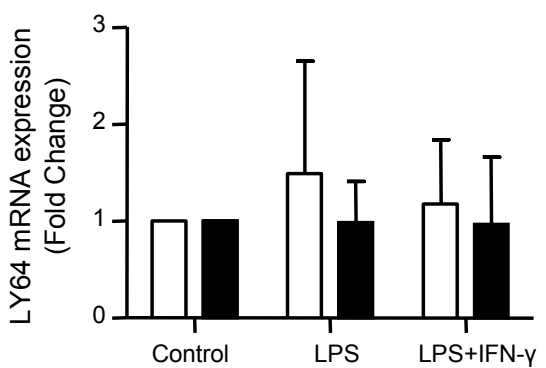

Figure 6 Gene expression restoration after incubation with recombinant IFN- $\gamma$ in whole blood of septic shock patients. Gene expressions of (a) TNF- $\alpha$, (b) IL-10, (c) HLA-DRA, (d) CIITA, (e) IRAK-M and (f) LY64 were quantified by quantitative RT-PCR in EDTA whole blood from eight septic shock patients sampled within three days after the onset of shock (black columns) and eight healthy volunteers (open columns), stimulated or not (control) with lipopolysaccharide (LPS; $100 \mathrm{ng} / \mathrm{ml}) \pm \mathrm{rlFN}-\gamma 1 \mathrm{~b}(100 \mathrm{ng} / \mathrm{ml})$ for one night. Data are presented as mean \pm standard deviation. Comparison between healthy volunteers and septic shock patients treated with LPS was performed using the MannWhitney $U$ test ( $* P<0.05$ ) whereas evaluation of rIFN-y effect was performed using the Wilcoxon signed rank test $(+P<0.05)$. IFN, interferon.

example, based on microarray data, Pachot et al. identified the loss of CX3CR1 as a new feature of sepsisinduced immunosuppression [25,35]. Wolk et al. observed that a reduction of CD86 mRNA expression level coupled with a low HLA-DR level is associated with an unfavorable prognosis in ICU patients with post-inflammatory immunodeficiency [36]. Recently, Hinrichs et al. followed the expression level of 23 mRNAs related to inflammation in patients after surgery [37]. They showed that TNF, IL1- $\beta, C D 3 D$ and PRF1 gene expressions were significantly different in patients who developed postoperative sepsis in comparison with patients who recovered uneventfully. In addition, their results demonstrate that the combination of TNF, IL1- $\beta$ and $C D 3 D$ mRNA expression levels is able to predict secondary infections with an extremely good area under the curve of 0.92 .

Our study has some limitations. First, as mentioned previously, seminal studies of immunostimulatory therapy in sepsis have shown that patients'stratification by their relative immunoparalysis, as evidenced by low circulating HLA-DR monocytes could improve treatment efficacy $[11,13]$. As this preliminary study was designed as a proof of concept to monitor response to ex vivo rIFN- $\gamma$ through the expression level of genes, this parameter, although included in the analysis, was not a 
criterion for patients' inclusion. Nevertheless, at the time of sampling, mHLA-DR expression in patients was decreased in comparison with normal values (Table 2). In further studies investigating this aspect, stratification based on mHLA-DR expression should be performed and it should be investigated whether ex vivo rIFN- $\gamma$ effect is more important in patients with low mHLA-DR expression. Second, the comparison between results in whole blood and in the model of ET shows some discrepancies. Without mentioning the difference in cell subpopulations, it is obvious that the mechanisms involved in monocyte dysfunctions partly differ between the two models. Indeed, ex vivo model of endotoxin tolerance uses only LPS to induce monocyte alterations whereas, in septic patients, many more parameters (IL-10, cortisol, treatments...) have been shown to impact monocyte functionality. This could explain differences between results obtained in ET model and in whole blood experiments. With that said, overall our results remain consistent between the two models.

\section{Conclusions}

As sepsis-acquired immunosuppression appears associated with increased risk of death and of nosocomial infection, immunostimulatory approaches able to restore cell dysfunctions represent innovative and promising therapeutic strategies. In this study, we propose to follow the expression levels of a panel of genes to assess $e x$ vivo monocyte-stimulating drug efficacy. The value of such biomarker panel deserves now to be evaluated in a large cohort of patients.

\section{Key messages}

- Recombinant human IFN- $\gamma$ increases TNF- $\alpha, H L A-$ $D R A$ and CIITA mRNA expression levels in an ex vivo model of ET and in cells from septic shock patients.

- Recombinant human IFN- $\gamma$ decreases IRAK-M and $A B I N-3$ mRNA expression levels in an ex vivo model of ET.

- This ex vivo translational research study demonstrates the potential of a mRNA-based approach to successfully monitor drug efficacy.

\section{Abbreviations}

ELISA: enzyme-linked immunosorbent assay; ET: endotoxin tolerance; IFN: interferon; IL: interleukin; LPS: lipopolysaccharide; PBMC: peripheral blood mononuclear cells; PBS: phosphate-buffered saline; PPIB: peptidylpropyl isomerase B; qRT-PCR: quantitative reverse-transcription polymerase chain reaction; SAPS II: simplified acute physiology score II; SOFA: Sequential Organ Failure Assessment; TLR: toll-like receptor; TNF: tumor necrosis factor.
\end{abstract}

\section{Acknowledgements}

This work conducted thanks to the logistical support ( $H$. Vallin) of the Centre $d^{\prime}$ Investigation Clinique (Clinical Research Center) of Inserm and Hospices Civils de Lyon. We would like to thank A. Portier and A. Villars-Mechin for their technical support. This project is part of Advanced Diagnostics for New Therapeutic Approaches, a program dedicated to personalized medicine, coordinated by Mérieux Alliance and supported by the French public agency, OSEO. GM, FV and AL are supported by the Hospices Civils de Lyon. GM is also supported by French ministry of health (PHRC interregional 2008) and DGOS-INSERM (Recherche clinique translationnelle 2009).

\section{Author details}

${ }^{1}$ BioMérieux, Joint Unit Hospices Civils de Lyon, Hôpital Edouard Herriot, 69003 Lyon, France. ${ }^{2}$ Cellular Immunology Laboratory, Hospices Civils de Lyon, Hôpital Edouard Herriot, 69003 Lyon, France. ${ }^{3}$ BioMérieux sa, F-69280 Marcy l'Etoile, France. ${ }^{4}$ Intensive Care Unit, Hospices Civils de Lyon, Centre Hospitalier Lyon-Sud, Chemin du Grand Revoyet, 69495 Pierre-Bénite, France.

\section{Authors' contributions}

FV conceived the study, participated in its design, in data analysis and drafted the manuscript. GM conceived the study, participated in its design, in data analysis, drafted the manuscript, revised the manuscript for intellectual content. CM, VB and EC participated in data acquisition and analysis. AL was involved in clinical samples and data acquisition. FTD established the PCR methodology, analysis, designed the primers, conceived the study, participated in its design, in data analysis and drafted the manuscript. AP and CAS revised the manuscript for intellectual content. All authors have read and approved the final manuscript for publication.

\section{Competing interests}

The authors declare that they have no competing interests.

Received: 7 July 2011 Revised: 29 July 2011 Accepted: 25 October 2011 Published: 25 October 2011

\section{References}

1. Hotchkiss RS, Karl IE: The pathophysiology and treatment of sepsis. N Engl J Med 2003, 348:138-150.

2. Monneret G, Venet F, Pachot A, Lepape A: Monitoring immune dysfunctions in the septic patient: a new skin for the old ceremony. Mol Med 2008, 14:64-78.

3. Munford RS, Pugin J: Normal responses to injury prevent systemic inflammation and can be immunosuppressive. Am J Respir Crit Care Med 2001, 163:316-321.

4. Carlet J, Cohen J, Calandra T, Opal SM, Masur H: Sepsis: time to reconsider the concept. Crit Care Med 2008, 36:964-966.

5. Carson WF, Cavassani KA, Dou Y, Kunkel SL: Epigenetic regulation of immune cell functions during post-septic immunosuppression. Epigenetics 2011, 6:273-283.

6. Cavaillon JM, Adib-Conquy M: Bench-to-bedside review: endotoxin tolerance as a model of leukocyte reprogramming in sepsis. Crit Care 2006, 10:233.

7. Biswas SK, Lopez-Collazo E: Endotoxin tolerance: new mechanisms, molecules and clinical significance. Trends Immunol 2009, 30:475-487.

8. Cavaillon JM, Adrie C, Fitting C, Adib-Conquy M: Reprogramming of circulatory cells in sepsis and SIRS. J Endotoxin Res 2005, 11:311-320.

9. Munoz C, Carlet J, Fitting C, Misset B, Bleriot JP, Cavaillon JM: Dysregulation of in vitro cytokine production by monocytes during sepsis. J Clin Invest 1991, 88:1747-1754.

10. Munoz C, Misset B, Fitting C, Bleriot JP, Carlet J, Cavaillon JM: Dissociation between plasma and monocyte-associated cytokines during sepsis. Eur J Immunol 1991, 21:2177-2184.

11. Docke WD, Randow F, Syrbe U, Krausch D, Asadullah K, Reinke P, Volk HD, Kox W: Monocyte deactivation in septic patients: restoration by IFNgamma treatment. Nat Med 1997, 3:678-681.

12. Lukaszewicz AC, Grienay M, Resche-Rigon M, Pirracchio R, Faivre V, Boval B, Payen D: Monocytic HLA-DR expression in intensive care patients: interest for prognosis and secondary infection prediction. Crit Care Med 2009, 37:2746-2752.

13. Nakos G, Malamou-Mitsi VD, Lachana A, Karassavoglou A, Kitsiouli E, Agnandi N, Lekka ME: Immunoparalysis in patients with severe trauma and the effect of inhaled interferon-gamma. Crit Care Med 2002, 30:1488-1494.

14. Landelle C, Lepape A, Voirin N, Tognet E, Venet F, Bohe J, Vanhems P, Monneret G: Low monocyte human leukocyte antigen-DR is 
independently associated with nosocomial infections after septic shock. Intensive Care Med 2010, 36:1859-1866.

15. Monneret G, Lepape A, Voirin N, Bohé J, Venet F, Debard AL, Thizy H, Bienvenu J, Gueyffier F, Vanhems P: Persisting low monocyte human leukocyte antigen-DR expression predicts mortality in septic shock. Intensive Care Med 2006, 32:1175-1183.

16. Pachot A, Blond JL, Mougin B, Miossec P: Peptidylpropyl isomerase B (PPIB): a suitable reference gene for mRNA quantification in peripheral whole blood. J Biotechnol 2004, 114:121-124.

17. Bone R, Balk R, Cerra F, Dellinger R, Fein A, Knaus W, Schein R, Sibbald W: Definitions for sepsis and organ failure and guidelines for the use of innovative therapies in sepsis. The ACCP/SCCM Consensus Conference Committee. American College of Chest Physicians/Society of Critical Care Medicine. Chest 1992, 101:1644-1655.

18. Le Gall J, Lemeshow S, Saulnier F: A new Simplified Acute Physiology Score (SAPS II) based on a European/North American multicenter study. JAMA 1993, 270:2957-2963.

19. Vincent JL, Moreno R, Takala J, Willatts S, De Mendonça A, Bruining H, Reinhart CK, Suter PM, Thijs LG: The SOFA (Sepsis-related Organ Failure Assessment) score to describe organ dysfunction/failure. On behalf of the Working Group on Sepsis-Related Problems of the European Society of Intensive Care Medicine. Intensive Care Med 1996, 22:707-710.

20. Adib-Conquy M, Cavaillon JM: Gamma interferon and granulocyte/ monocyte colony-stimulating factor prevent endotoxin tolerance in human monocytes by promoting interleukin-1 receptor-associated kinase expression and its association to MyD88 and not by modulating TLR4 expression. J Biol Chem 2002, 277:27927-27934.

21. Kylanpaa ML, Mentula P, Kemppainen E, Puolakkainen P, Aittomaki S, Silvennoinen $\mathrm{O}$, Haapiainen $\mathrm{R}$, Repo $\mathrm{H}$ : Monocyte anergy is present in patients with severe acute pancreatitis and is significantly alleviated by granulocyte-macrophage colony-stimulating factor and interferongamma in vitro. Pancreas 2005, 31:23-27.

22. Randow F, Docke WD, Bundschuh DS, Hartung T, Wendel A, Volk HD: In vitro prevention and reversal of lipopolysaccharide desensitization by IFN-gamma, IL-12, and granulocyte-macrophage colony-stimulating factor. J Immunol 1997, 158:2911-2918.

23. Hotchkiss RS, Coopersmith CM, McDunn JE, Ferguson TA: The sepsis seesaw: tilting toward immunosuppression. Nat Med 2009, 15:496-497.

24. Cavaillon JM, Adrie C, Fitting C, Adib-Conquy M: Endotoxin tolerance: is there a clinical relevance? J Endotoxin Res 2003, 9:101-107.

25. Pachot A, Cazalis MA, Venet F, Turrel F, Faudot C, Voirin N, Diasparra J, Bourgoin N, Poitevin F, Mougin B, Lepape A, Monneret G: Decreased expression of the fractalkine receptor CX3CR1 on circulating monocytes as new feature of sepsis-induced immunosuppression. J Immunol 2008, 180:6421-6429.

26. Wolk K, Docke WD, von Baehr V, Volk HD, Sabat R: Impaired antigen presentation by human monocytes during endotoxin tolerance. Blood 2000, 96:218-223.

27. Wolk K, Kunz S, Crompton NE, Volk HD, Sabat R: Multiple mechanisms of reduced major histocompatibility complex class II expression in endotoxin tolerance. J Biol Chem 2003, 278:18030-18036.

28. Chen J, Ivashkiv LB: IFN-gamma abrogates endotoxin tolerance by facilitating Toll-like receptor-induced chromatin remodeling. Proc Nat/ Acad Sci USA 2010, 107:19438-19443.

29. Escoll P, del Fresno C, Garcia L, Valles G, Lendinez MJ, Arnalich F, LopezCollazo E: Rapid up-regulation of IRAK-M expression following a second endotoxin challenge in human monocytes and in monocytes isolated from septic patients. Biochem Biophys Res Commun 2003, 311:465-472.

30. Verstrepen L, Adib-Conquy M, Kreike M, Carpentier I, Adrie C, Cavaillon JM, Beyaert R: Expression of the NF-kappaB inhibitor ABIN-3 in response to TNF and toll-like receptor 4 stimulation is itself regulated by NF-kappaB. J Cell Mol Med 2008, 12:316-329.

31. Divanovic S, Trompette A, Atabani SF, Madan R, Golenbock DT, Visintin A, Finberg RW, Tarakhovsky A, Vogel SN, Belkaid Y, Kurt-Jones EA, Karp CL: Negative regulation of Toll-like receptor 4 signaling by the Toll-like receptor homolog RP105. Nat Immunol 2005, 6:571-578.

32. Pachot $A$, Monneret $G$, Brion A, Venet $F$, Bohe J, Bienvenu J, Mougin B, Lepape A: Messenger RNA expression of major histocompatibility complex class II genes in whole blood from septic shock patients. Crit Care Med 2005, 33:31-38.
33. Monneret G, Venet F, Meisel C, Schefold JC: Assessment of monocytic HLA-DR expression in ICU patients: analytical issues for multicentric flow cytometry studies. Crit Care 2010, 14:432.

34. Turrel-Davin F, Guignant C, Lepape A, Mougin B, Monneret G, Venet F: Upregulation of the pro-apoptotic genes BID and FAS in septic shock patients. Crit Care 2010, 14:R133.

35. Pachot A, Lepape A, Vey S, Bienvenu J, Mougin B, Monneret G: Systemic transcriptional analysis in survivor and non-survivor septic shock patients: a preliminary study. Immunol Lett 2006, 106:63-71.

36. Wolk K, Hoflich C, Zuckermann-Becker H, Docke WD, Volk HD, Sabat R: Reduced monocyte CD86 expression in postinflammatory immunodeficiency. Crit Care Med 2007, 35:458-467.

37. Hinrichs C, Kotsch K, Buchwald S, Habicher M, Saak N, Gerlach H, Volk HD, Keh D: Perioperative gene expression analysis for prediction of postoperative sepsis. Clin Chem 2010, 56:613-622.

doi:10.1186/cc10513

Cite this article as: Turrel-Davin et al:: mRNA-based approach to monitor recombinant gamma-interferon restoration of LPS-induced endotoxin tolerance. Critical Care 2011 15:R252.

\section{Submit your next manuscript to BioMed Central and take full advantage of:}

- Convenient online submission

- Thorough peer review

- No space constraints or color figure charges

- Immediate publication on acceptance

- Inclusion in PubMed, CAS, Scopus and Google Scholar

- Research which is freely available for redistribution 